\title{
Autumn migration direction of juvenile willow warblers (Phylloscopus t. trochilus and $P$. t. acredula) and their hybrids assessed by qPCR SNP genotyping
}

Tianhao Zhao ${ }^{1}$, Mihaela llieva², Keith Larson ${ }^{3}$, Max Lundberg ${ }^{1}$, Júlio M. Neto ${ }^{1}$, Kristaps Sokolovskis ${ }^{1}$, Susanne Åkesson ${ }^{4}$ and Staffan Bensch ${ }^{*}$

\begin{abstract}
Backgrounds: Geographic regions, where two closely related taxa with different migration routes come into contact, are known as migratory divides. Hybrids originating from migratory divides are hypothesized to migrate intermediately relative to the parental populations. Few studies have tested this hypothesis in wild birds, and only in hybrids that have completed the migration back to the breeding grounds. Here, we make use of the wellestablished migration routes of willow warblers (Phylloscopus trochilus), for which the subspecies trochilus and acredula have migration-associated genetic markers on chromosomes 1 and 5 . The genetic approach enabled us to analyze the geographic distribution of juveniles during their first autumn migration, predicting that hybrids should be more frequent in the central flyway over Italy than along the typical SW routes of trochilus and SE routes of acredula.
\end{abstract}

Methods: Blood and feather samples were collected from wintering birds in Africa ( $n=69)$, and from juveniles during autumn migration in Portugal $(n=33)$, Italy $(n=38)$ and Bulgaria $(n=32)$. Genotyping was carried out by qPCR SNP assays, on one SNP each on chromosome 1 (SNP 65) and chromosome 5 (SNP 285). Both these SNPs have alternative alleles that are highly fixed (>97\%) in each of the subspecies.

Results: The observed combined genotypes of the two SNPs were associated with the known migration routes and wintering distributions of trochilus and acredula, respectively. We found hybrids $(\mathrm{HH})$ among the juveniles in Italy (5/38) and in Portugal (2/33). The proportion of hybrids in Italy was significantly higher than expected from a background rate of hybrid genotypes (1.5\%) in allopatric populations of the subspecies.

(Continued on next page)

\footnotetext{
* Correspondence: staffan.bensch@biol.lu.se

'Department of Biology, Molecular Ecology and Evolution Laboratory, Lund University, Ecology Building, 22362 Lund, SE, Sweden

Full list of author information is available at the end of the article
}

(c) The Author(s). 2020 Open Access This article is licensed under a Creative Commons Attribution 4.0 International License, which permits use, sharing, adaptation, distribution and reproduction in any medium or format, as long as you give appropriate credit to the original author(s) and the source, provide a link to the Creative Commons licence, and indicate if changes were made. The images or other third party material in this article are included in the article's Creative Commons licence, unless indicated otherwise in a credit line to the material. If material is not included in the article's Creative Commons licence and your intended use is not permitted by statutory regulation or exceeds the permitted use, you will need to obtain permission directly from the copyright holder. To view a copy of this licence, visit http://creativecommons.org/licenses/by/4.0/ The Creative Commons Public Domain Dedication waiver (http://creativecommons.org/publicdomain/zero/1.0/) applies to the data made available in this article, unless otherwise stated in a credit line to the data. 


\begin{abstract}
(Continued from previous page)
Conclusions: Our genetic approach to assign individuals to subspecies and hybrids allowed us to investigate migration direction in juvenile birds on their first migration, which should better reflect the innate migratory direction than studies restricted to successful migrants. The excess of hybrids in Italy, suggests that they employ an intermediate route relative to the parental populations. Our qPCR SNP genotyping method is efficient for processing large sample sizes, and will therefore be useful in migration research of species with known population genetic structure.
\end{abstract}

Keywords: Bird migration, Genetic migration program, Migratory divide, Intermediate route, SNP genotyping, Hybrid genotype, Phylloscopus trochilus

\section{Introduction}

Migratory divides, defined as geographic regions where the ranges of two closely related taxa that differ in migration routes come into contact and interbreed, are described from several avian species in Europe [1], Asia [2] and North America [3]. It has been proposed that migratory divides are maintained by selection against hybrids $[1,3-5]$. This idea is based on the hypothesis that hybrids migrate along an intermediate direction relative to their parents, and that such routes confer lower survival, requiring hybrids to cross major geographical barriers, e.g. oceans (Mediterranean Sea [6]), deserts (Sahara [7]) or mountain ranges (Qinghai-Tibetan Plateau [2]).

The "intermediate route" hypothesis has been investigated by various methods. The classic studies of experimentally cross-bred blackcaps from populations with SW and SE migration, respectively, used orientation cages to demonstrate that F1 hybrids exhibited an intermediate direction towards south [8]. However, initial migration directions measured in orientation experiments may not be representative to the migration routes of hybrids in the wild, and thus other methods are required for obtaining data on migration routes and wintering areas. The first attempts to investigate the migration routes of hybrids in the wild made use of stable isotope analyses of feathers moulted at the wintering grounds [5, $9,10]$. These studies suggested that hybrids between two species of flycatchers and between Acrocephalus warblers occupied wintering areas, and presumably used migration routes, that were similar to one of the parental species rather than migrating intermediately. However, these results should be cautiously interpreted because stable isotype analyses are known to have low precision when predicting moulting areas of individual birds [5, $10,11]$ and the link between migration routes and wintering areas may not be straightforward. More detailed information about the migration routes was obtained by Delmore et al. (2014) who used light-level geolocators to track 15 hybrids between the coastal and inland subspecies of the Swainson's thrush (Catharus ustulatus), two populations previously documented to show different migration routes and wintering areas [12, 13]. About half of the hybrids displayed an intermediate migratory behavior, providing the strongest evidence so far for the "intermediate route" hypothesis. However, studies based on stable isotope analyses and tracks from geolocators have the inherited constraint that the wintering areas and migration routes can only be obtained from successfully migrating individuals, i.e. those that managed to return from the winter quarters to the breeding sites. If selection operates against first-time (juvenile) migrants employing the intermediate route, these will be underestimated in any study based on analyses of returning birds. Among other methodologies for studying migration, GPS transmitters are hitherto too big for most of the songbirds [14]. Telemetry studies require a dense network of e.g. MOTUS receivers to function in a large geographic range to provide meaningful route details [15], which is not yet in place for studies of songbirds that have migratory divides. Hence, other approaches are needed to obtain unbiased estimates of migration routes taken by first-time juvenile migratory birds, e.g. genetic tools $[16,17]$.

The willow warbler Phylloscopus trochilus is a smallsized long-distance migratory songbird that breeds in the northern parts of the Palearctic from western Europe to eastern Siberia [18]. Its wintering grounds are located in sub-Saharan Africa as supported by ringing recoveries [19] and tracks obtained from light-level geolocators [20, 21]. Two subspecies occur in the western part of its range; $P$. t. trochilus and $P$. $t$. acredula. Despite slight but significant average differences in coloration and morphometrics, individuals cannot accurately be assigned to subspecies (or hybrids) due to extensive overlap in the phenotype [22]. The subspecies trochilus breeds in western Europe and southern Scandinavia, and migrates through western Europe to wintering grounds in western Africa. The subspecies acredula breeds in eastern Europe and northern Scandinavia and migrates through eastern Europe to wintering grounds in eastern and southern Africa. The trochilus and acredula populations meet in a well-defined contact zone in central Scandinavia and in a broader more diffuse zone in Poland [22] (Fig. 1). 


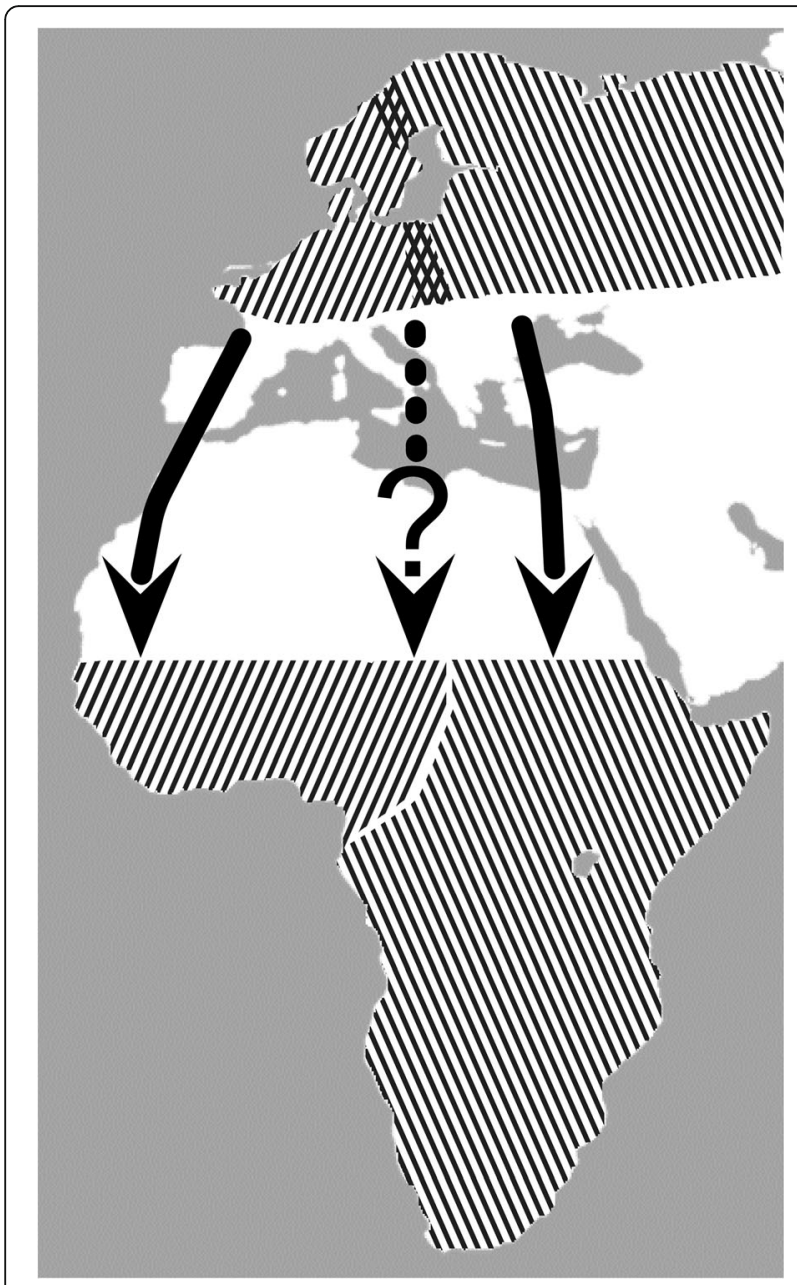

Fig. 1 Approximate breeding and wintering ranges of the two subspecies of willow warblers, and their contact zones (migratory divides) in Scandinavia and Poland indicated by the range overlap. The subspecies trochilus migrates SW through Iberian Peninsula and winters in western Africa, whereas subspecies acredula migrates SSE through eastern Europe and winters in eastern to southern Africa. The hybrids originating from the migratory divides are hypothesized to migrate intermediately relative to the parental routes

The willow warbler has been a focal species for research on genetics of migration for two decades [21-28]. Stable isotope analyses $\left(\delta^{15} \mathrm{~N}\right)$ of winter moulted feathers have revealed that there is a distinct migratory divide in central Scandinavia $[22,23,28]$ where the two subspecies mate at random [27] and hybrids are frequent [28]. In the migratory divide, the population average $\delta^{15} \mathrm{~N}$ is between the values of allopatric trochilus and acredula, respectively [23]. However, this data cannot distinguish whether hybrids are migrating intermediately relative the parental forms or whether the migratory divide consist of a mix of birds with either typical trochilus or acredula migratory directions.

The genomes between the subspecies are virtually undifferentiated except in three well-defined chromosome regions [25, 28]. The very limited recombination between the subspecies in these regions gives rise to sets of long-range northern and southern haplotypes. The geographic distributions of the northern and southern haplotypes in two of the divergent regions (chromosome 1 and 5) perfectly match the location of the migratory divides, suggesting that these genomic regions contain genes associated with the migratory behavior [28]. The highly fixed SNPs (Single Nucleotide Polymorphisms) in each of these regions can therefore be used to assign individuals to each subspecies (trochilus and acredula) and to identify hybrids.

In this study, we investigated how juvenile willow warblers migrate in their first autumn migration by using SNP genotyping methods based on qPCR (quantitative Polymerase Chain Reaction). This methodology allows us to identify subspecies and hybrids among birds caught during the non-breeding season. We first tested the power of the assay by analyzing samples of willow warblers from the African wintering grounds with the expectation to find the trochilus genotypes in western Africa and the acredula genotype in eastern and southern Africa. Next, we set up three predictions for the juvenile birds captured during autumn migration. (1) Samples from western Europe (Portugal) will be dominated by the "trochilus" genotype. (2) Samples from eastern Europe (Bulgaria) will be dominated by the acredula genotype. (3) If F1 hybrid juveniles between acredula and trochilus exist, they will be over-represented in central southern Europe (Italy) according to the intermediate route hypothesis. This approach circumvents the limitations of stable isotope and geolocator studies, as willow warblers were sampled during their first autumn migration before reaching the major ecological barriers (the Mediterranean Sea and the Sahara Desert) that presumably cause greater mortality to the maladapted hybrids and thereby will provide an accurate measure of realized migratory directions of first-year hybrids.

\section{Methods and materials}

\section{Study species and sampling locations}

We genotyped individual willow warblers from blood and feather DNA samples collected from breeding grounds in Scandinavia, during autumn migration at three locations in southern Europe and on wintering grounds in Africa (Table S1). To determine the genotype frequencies of allopatric trochilus and acredula, we used samples from previous publications [22] that consisted of territorial males from southern Scandinavia (Denmark and southern Sweden, latitude between $55^{\circ}-60^{\circ}, n=66$ ) and northern Scandinavia (Finland, Norway and northern Sweden, latitude above $65^{\circ}, n=60$ ); both data sets are from areas well outside the contact zones. The autumn migration samples were collected between 
August-October in Portugal $(n=33)$, Italy $(n=38)$ and Bulgaria $(n=32)$. The samples from the wintering range (November-April) were collected in Ivory Coast $(n=$ $12)$, Cameron $(n=27)$, Kenya $(n=3)$, Tanzania $(n=4)$, Zambia $(n=15)$ and South Africa $(n=8)$.

\section{DNA extraction and quantification}

Birds were captured in mist-nets and from each individual $\sim 20-50 \mu \mathrm{l}$ of blood was taken from the brachial vein and stored in SET buffer $(0.15 \mathrm{M} \mathrm{NaCl}, 0.001 \mathrm{M}$ EDTA and $0.05 \mathrm{M}$ Tris). Genomic DNA was extracted using an ammonium acetate protocol [29] and diluted to a concentration of $\sim 1 \mathrm{ng} / \mu \mathrm{l}$.

The base of feather samples $(\sim 5 \mathrm{~mm}$ of either tail feathers or innermost primary flight feathers) were cut into two strips to expose the inner structure, and added to tubes with $100 \mu \mathrm{l}$ lysis buffer and 1.5 proteinase $\mathrm{K}$ and incubated at $56^{\circ} \mathrm{C}$ for $3 \mathrm{~h}$ with regular shaking every hour. Following the digestion, $10 \mu \mathrm{l}$ Sodium Acetate (NaAc) (3 M) and $220 \mu \mathrm{l} 95 \%$ cold ethanol was used to precipitate the DNA. The DNA was pelleted by high speed centrifugation and the pellet was washed in $100 \mu \mathrm{l}$ $70 \%$ cold ethanol. The extracted DNA was dissolved in $1 \mathrm{xTE}$ and diluted to a concentration of $\sim 2 \mathrm{ng} / \mu \mathrm{l}$.

\section{SNP selection}

A previous study based on whole-genome resequencing and genotyping by a SNP array [28] identified two large blocks on chromosome $1(13 \mathrm{Mb})$ and chromosome 5 (4 $\mathrm{Mb})$ that carried highly divergent and non-recombining haplotypes between southern (trochilus) and northern populations (acredula). From the set of variants called from the resequencing data of nine southern and nine northern willow warblers [28], we first selected four highly differentiated SNPs (two per chromosome) for developing qPCR assays for differentiating trochilus and acredula. We named the two on chromosome 1 " 23 " and " 65 ", and the two on chromosome 5 " 285 " and "412", corresponding to the scaffolds on which they were located (Figure S1). All the selected SNPs were located within regions of $200 \mathrm{bp}$ that in the resequencing data contained very few SNPs, in order to avoid having primers and probes overlapping polymorphic sites.

\section{Primer and probes}

We used Thermo Fisher's online Custom TaqMan ${ }^{\circ}$ Assay Design Tool to design the probes and primers for all the four SNPs. For each SNP, a 400 bp sequence with the target SNP in the middle was submitted to the server, in which all other irrelevant SNPs were marked as "N". The tool then automatically generated the forward and reverse primers as well as the probes to detect different alleles of the target SNPs. Fluorophores attached to the beacons to differentiate alleles were FAM and
VIC. The designed primers and probes, are given in Table S2.

\section{SNP genotyping}

The genotyping of the target SNPs where done using either of two different qPCR instruments; a MX3005P (Stratagene, La Jolla, CA, USA) or a BioRad CFX96 ${ }^{\text {tm }}$ Real-time PCR system (Bio-Rad Laboratories, CA, USA). On both instruments we used the universal Fast-twosteps protocol $\left(95^{\circ} \mathrm{C}, 15 \mathrm{~min}-40^{*}\left(95^{\circ} \mathrm{C}, 10 \mathrm{~s}-60^{\circ} \mathrm{C}\right.\right.$, $30 \mathrm{~s}$, plate read)).

Samples were run in $10 \mu \mathrm{l}$ volumes with $5 \mu \mathrm{l} \mathrm{TaqMan}{ }^{\circ}$ Genotyping Master Mix, $0.5 \mu \mathrm{l} 20 \mathrm{X}$ genotype assay (containing primers and probes) and $4.5 \mu$ l diluted DNA samples $(\sim 2 \mathrm{ng} / \mu \mathrm{l}$ for feather DNA samples and $\sim 1 \mathrm{ng} /$ $\mu \mathrm{l}$ for blood DNA samples). We first tested the genotype assays on DNA from both blood and feathers for a limited number of samples $(n=8)$ with duplicates, to examine the consistency and success rate of this strategy. We also examined blood and feather DNA samples from the same individuals $(n=21)$ to confirm the repeatability of DNA sample from different resources. The qPCRs for all the samples in the present study were run on 96-plates including both negative and two positive controls. The positive controls consisted of samples with genotypes fixed for either of the two different alleles.

We used the allelic discrimination functions provided by the software of the two qPCR instruments to generate the scatterplots of the fluorescence signals; Bio-Rad CFX Maestro $^{\text {Tx }} 1.1$ software and Mx3005P qPCR software, respectively. Examples of the results are illustrated in Figure S2a (Bio-Rad CFX) and Figure S2b (Mx3005P).

\section{Consistency and fixation levels of the analyzed SNPs}

We used the above mentioned pure trochilus and acredula breeding samples from Scandinavia to evaluate how well the single SNPs can be used to predict the haplotype assignment on the regions of chromosomes 1 and 5 , as well as their fixation level, i.e. allele frequencies in the two populations. From the SNP array [28], each individual had previously been classified as northern homozygous, southern homozygous or heterozygous for the regions on chromosome 1 and 5 based on a multidimensional scaling (MDS) analysis of 108 and 31 SNPs, respectively. We found that the single SNPs genotyped by $\mathrm{qPCR}$ were generally good at predicting the haplotypes assigned by the SNP array [28] (Table S3). The consistency ratios for chromosome 1 were $95.9 \%$ for SNP 23 and 99.0\% for SNP 65. For chromosome 5, both SNP 285 and SNP 412 had a consistency ratio of 97.3\%. This demonstrates that each of the selected SNPs has a high power to correctly assign the haplotype blocks as trochilus and acredula, respectively. 
All the four investigated SNPs showed a high level of fixation of the presumed subspecies-specific alleles (Table 1, Figure S3). Based on these results (consistency rates with the SNP array and fixation levels), we selected SNP 65 on chromosome 1 and SNP 285 on chromosome 5 for population assignment. The other two SNPs were used for verifying hybrid genotypes.

\section{Assignment of genotypes}

Our selected SNPs were all bi-allelic, so for each SNP locus there are three possible genotypes, denoted by $\mathrm{N}$ for the northern homozygous genotype, $\mathrm{H}$ for the heterozygous genotype, and $\mathrm{S}$ for the southern homozygous genotype. As we were using two SNPs (65 from chromosome 1 and 285 from chromosome 5), there are 9 possible combined genotypes: $\mathrm{NN}, \mathrm{NH}, \mathrm{HN}, \mathrm{NS}, \mathrm{HH}, \mathrm{SN}$, $\mathrm{SH}, \mathrm{HS}$ and SS. We used the allele frequencies in the southern and northern Scandinavian willow warbler populations (Table 1) to estimate the expected occurrence rate of each genotype within these populations, under the assumption of Hardy-Weinberg equilibrium (Table 2).

The chance of finding the genotypes $\mathrm{SS}$ and $\mathrm{SH}$ are much higher (45,000 and 148 times more likely) in a southern than in a northern population (Table 2). Likewise, each of the genotypes NN, NH and $\mathrm{HN}$ are $>2600$ times more likely to be found in an acredula than in a trochilus population. Importantly, the occurrence probabilities of heterozygotes $(\mathrm{HH})$ or mismatching homozygotes (SN, NS) were low $(<1.5 \%)$ in both the southern and northern populations (Table 2). Based on these calculations, we conclude that genotypes $\mathrm{HH}, \mathrm{SN}$ and NS are extremely unlikely to originate from populations of pure trochilus or acredula.

For the following analyses we therefore assume that genotypes SS, HS and SH mostly originate from populations of allopatric trochilus and individuals with the genotypes $\mathrm{NN}, \mathrm{NH}$ and $\mathrm{HN}$ from populations of allopatric acredula. We further assume that the genotypes $\mathrm{HH}$ consist of F1 hybrid offspring from (trochilus $\mathrm{x}$ acredula) and originate from any of the two migratory

Table 1 Allele frequencies of the four selected SNPs in southern and northern Scandinavian populations of willow warblers

\begin{tabular}{lll}
\hline SNP & Allele frequencies & \\
\cline { 2 - 3 } & $\begin{array}{l}\text { Southern population } \\
(n=66)\end{array}$ & $\begin{array}{l}\text { Northern population } \\
(n=60)\end{array}$ \\
\hline $23(\mathrm{~T} / \mathrm{G})$ & $0.955 / 0.045$ & $0.050 / 0.950$ \\
$65(\mathrm{C} / \mathrm{A})$ & $0.985 / 0.015$ & $0.050 / 0.950$ \\
$285(\mathrm{~A} / \mathrm{G})$ & $0.970 / 0.030$ & $0.084 / 0.916$ \\
$412(\mathrm{G} / \mathrm{A})$ & $0.963 / 0.037$ & $0.091 / 0.908$
\end{tabular}

SNP 23 and 65 are located on chromosome 1, SNP 285 and 412 on chromosome 5 , respectively divides, as do the genotypes $\mathrm{SN}$ and NS which are likely to be $\mathrm{F} 2$ offspring from $\mathrm{HH} \times \mathrm{HH}$ parents. To confirm genotypes of the supposed hybrid individuals, we genotyped these samples for the additional SNPs (23 and 412). Willow warblers that showed the same hybrid genotype for the two sets of SNPs were classified as hybrids. Three birds had mismatching genotypes for the two SNPs on the same chromosome and were classified as "undefined". Note that this is not a technical genotyping problem, but a consequence of the nucleotides not being fixed for the alternative variants in the reference populations (Table 1 ).

We used a Binomial Probability Test to estimate whether the F1 heterozygotes $(\mathrm{HH})$ were overrepresented in migratory sampling sites.

\section{Results}

\section{Genotypes in winter samples from Africa}

The genotype compositions differed markedly between western compared to eastern and southern Africa (Fig. 2a). In western Africa (Ivory Coast $(n=12)$ and Cameroon $(n=27), 97.3 \%$ of the individuals were assigned to trochilus, and one individual was assigned to acredula. In eastern Africa (Kenya $(n=3)$, Tanzania $(n=$ $4)$, Zambia $(n=15)$ and South Africa $(n=8))$, all individuals were assigned to acredula. Among the winter samples, we did not find any individual with a presumed origin from the hybrid zones $(\mathrm{HH}, \mathrm{SN}$ or NS individuals).

\section{Genotyping results of juvenile birds captured during autumn migration in Europe}

Juveniles sampled in Portugal, Italy and Bulgaria clearly had different genotype compositions (Fig. 2b). In Portugal, $87.9 \%(n=33)$ of the individuals were assigned to trochilus, and of the remaining, two were $\mathrm{HH}$, one $\mathrm{SN}$ and one NS. The analyses of SNP 23 and 412 confirmed these hybrid genotypes. In Bulgaria, 93.8\% $(n=32)$ of the individuals were assigned to acredula. Of the remaining two birds, one was assigned to trochilus and one as undefined genotype (northern or F2). In Italy, 63.2\% ( $n=$ 38 ) of the individuals were assigned to acredula, $13.2 \%$ to trochilus, five birds were $\mathrm{HH}$, one $\mathrm{SN}$ and one NS. The analyses of SNP 23 and 412 confirmed these hybrid genotypes. However, the genotypes of two birds could not be resolved (one was F2 or hybrid, the other southern or hybrid). By assuming a background level of heterozygote individuals $(\mathrm{HH})$ of $1.5 \%$ in allopatric trochilus and acredula populations (Table 2), we observed that $\mathrm{HH}$ individuals were significantly over-represented in Italy (Binomial Probability Test, $p$-value $=0.00023$ ) Based on the same assumption, the $\mathrm{HH}$ individuals were not significantly over-represented in Portugal (Binomial 
Table 2 Expected occurrence rate of each genotype in southern and northern populations calculated from the subspecies-specific allele frequencies (Table 1) under the assumption of Hardy-Weinberg Equilibrium and similar population size between southern and northern population

\begin{tabular}{llll}
\hline Genotype & \multicolumn{2}{l}{ Expected occurrence rate } & Log likelihood ratio $^{a}$ \\
\cline { 2 - 4 } & Southern population & Northern population & 4.659 \\
\hline SS & $91.288 \%$ & $0.002 \%$ & 2.172 \\
SH & $5.647 \%$ & $0.038 \%$ & 1.631 \\
HS & $2.780 \%$ & $0.065 \%$ & 0.382 \\
SN & $0.087 \%$ & $0.210 \%$ & 0.924 \\
HH & $0.172 \%$ & $1.446 \%$ & 1.471 \\
NS & $0.021 \%$ & $0.622 \%$ & 3.425 \\
HN & $0.003 \%$ & $7.988 \%$ & 4.137 \\
NH & $0.001 \%$ & $13.738 \%$ & 4.926 \\
NN & $0.000 \%$ & $75.890 \%$ & \\
\hline
\end{tabular}

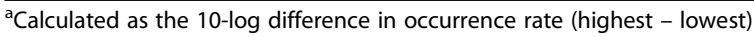

Probability Test, $p$-value $=0.07$ ) or in Bulgaria (Binomial Probability Test, $p$-value $=0.62$ ) .

\section{Discussion}

In this study, we used genotype assignments to investigate the autumn migratory direction of juvenile willow warblers. This indirect, though unbiased approach, allowed us to test whether juvenile F1 hybrids between the subspecies trochilus and acredula migrate along directions similar to either of the parental forms, or if they follow an intermediate route as has been proposed for hybrid willow warblers [24], and several other species having narrow migratory divides $[13,30]$. We first demonstrated that the two SNP markers used for this study are highly fixed between the subspecies trochilus and acredula, and that hybrid individuals have a high likelihood of origin from the migratory divides. We tested the SNP assay on willow warbler samples from winter quarters in Africa, and found that trochilus and acredula exclusively (except for one acredula in Ivory Coast in April) occurred in western and eastern Africa, respectively, in line with the well-documented wintering quarters of the subspecies $[11,19,23]$. We can think of two explanations to why we did not find any hybrids among the samples from Africa. First, if hybrids tend, as predicted, to winter in Central Africa, this region is not represented among our available samples. Second, if they winter throughout the range of both subspecies, their frequency at any location would be very low and thus likely to be missed due to our small sample size $(n=69)$.

During autumn migration in southern Europe, juvenile trochilus and acredula dominated in western (Portugal) and eastern Europe (Bulgaria), respectively, also in line with the well documented autumn migration directions of these subspecies $[19,22]$.
Among the autumn samples, we identified seven birds as F1 hybrids. Although the two investigated SNPs are not completely fixed for the alternative alleles in allopatric trochilus and acredula populations, our calculations show that F1 individuals are expected to occur at very low frequencies in the allopatric populations $(0.172 \%$ in trochilus and $1.446 \%$ in acredula). Because our references samples for allopatric trochilus and acredula were collected relatively close to the migratory divides compared to the huge allopatric ranges of the subspecies, a background frequency of hybrid genotypes $<1.5 \%$ is deemed a conservative estimate. In line with this, Lundberg et al. (2017) reported that populations most distant from the migratory divides (Denmark and UK representing the trochilus haplotype and southern Finland and Siberia representing the acredula haplotype) were completely fixed for the subspecies specific haplotypes, both for chromosome 1 and 5 [28].

In the Scandinavian migratory divide, $27 \%$ of the territorial (adult) males are hybrids $(\mathrm{HH})$ or conflicting homozygotes (NS and SN) [28]. Hence, most (if not all) F1 hybrids that we recorded are likely to have originated from the migratory divides in Scandinavia or Poland. During autumn migration in southern Europe, the juvenile F1 hybrid individuals were significantly over-represented in the sample from Italy, rarely shown in Portugal and absent in Bulgaria. This result is in line with the expected intermediate route, if these hybrids originated from any of the two contact zones in Scandinavia or Poland.

The overrepresentation of heterozygous juvenile willow warblers (F1 hybrids) in Italy during autumn migration suggests that hybrids migrate along an intermediate route during their first migration relative to their parental populations, in line with the hypothesis proposed by Helbig [8]. This interpretation 

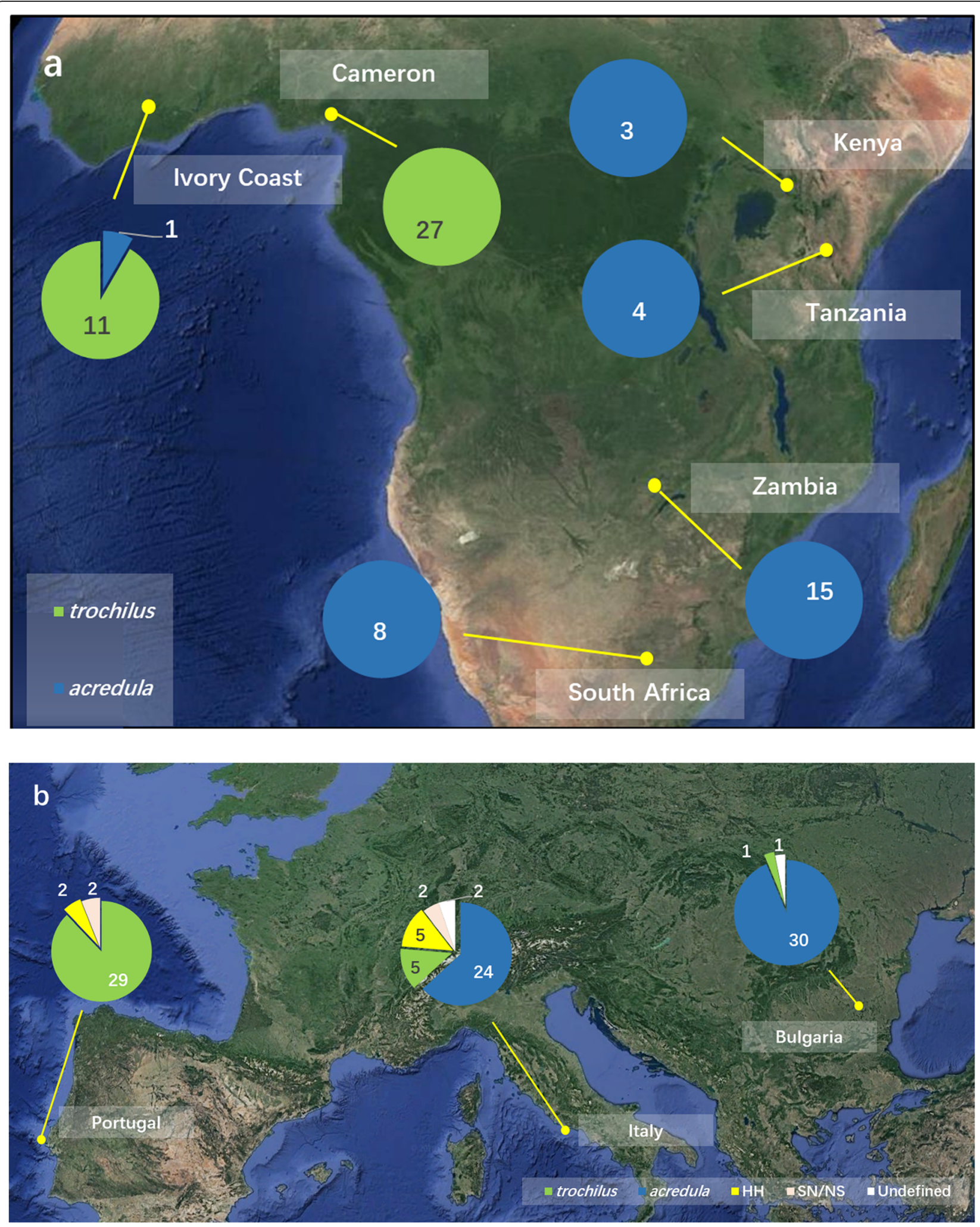

Fig. 2 (See legend on next page.) 
(See figure on previous page.)

Fig. 2 Genetic assignments of willow warblers at sampling sites in a. Africa (November - April) and b. juveniles during autumn migration (August - October) in southern Europe. Genotypes "SS", "HS", "SH" were assigned as the subspecies trochilus and "NN", "NH", "HN" as the subspecies acredula. "HH" represents F1 hybrids and "SN/NS" F2 hybrids as verified with the other two SNPs. Three potential hybrid individuals carried conflicting genotypes for SNPs within chromosomes and are shown as "Undefined". Sample sizes: Ivory Coast, $n=12 ;$ Cameron, $n=27 ;$ Kenya, $n=3$; Tanzania, $n=4$; Zambia, $n=15$; South Africa, $n=8$; Portugal, $n=33$; Italy, $n=38$; Bulgaria, $n=32$

implies that the genes encoding migration direction, in the willow warbler presumed to be located on the blocks on chromosome 1 and 5 [28], have a codominant effect on the phenotype. However, in conflict to this conclusion are our records of two hybrids in Portugal, clearly resembling the routes of pure trochilus. Similar results were shown in the isotope studies in the flycatchers [9] and Acrocephalus warblers [10], where the hybrids migrated southwest as one of the parents. The two Portuguese willow warbler hybrids were captured in two different years (2011 and 2012), and thus it is unlikely that their presence in Portugal was due to unusual weather conditions. To identify which of the genes in the differentiated chromosome regions that may determine migratory direction, will require data on the migratory routes for a larger sample of hybrids, F2's and back-crossed individuals, as well as samples from a wider geographical range. Eventually, such data may enable us to investigate the dominance pattern of the genes, as well as whether there are other overlooked genomic regions responsible for the migration direction.

The intermediate route of hybrids has been suggested to function as a post-zygotic reproductive isolation mechanism, maintaining migratory divides. In willow warblers, the intermediate route passes over the central Mediterranean Sea and the Sahara Desert, which are commonly regarded as ecological barriers $[6,7]$, and therefore would induce higher mortality rates than the parental routes to Africa, east or west of these barriers. However, the route across the central Mediterranean Sea is nonetheless a major migration route for some other species of songbirds, e.g. wood warblers [31] and sedge warblers [32]. It is possible that these species are better-adapted to this route than hybrid willow warblers, by for example putting on more fat reserves before crossing the Sahara. Because there is a substantial proportion of breeding willow warblers of hybrid origin in the migratory divides [28], i.e. birds that have completed the migration to and back from the wintering grounds, the annual mortality of hybrids cannot be very different from the mortality of the parental forms. From the equation in Barton and Hewitt (1985) [33], and using estimates of dispersal distances $(\sigma \cong 80 \mathrm{~km})$ and width of the hybrid zone $(250 \mathrm{~km})$ [22], we can calculate that the selection against hybrids is $\sim 10 \%$ per generation. This rough estimate would scale to a reduction of hybrid survival from e.g. 50 to $45 \%$. i.e. a difference large enough to keep the width of the hybrid zone. However to statistically verify such a small difference would require survival data for $>1000$ individuals.

In contrast to experienced adult migrants, as solitary migrants, juveniles have to rely on their endogenous navigation system and the inherited direction or "goal" as guidance [34]. The lack of previous experience increases the risk that they become disoriented [35-37]. We therefore expect that the direction differences observed among juveniles will be larger than among adults [38-41]. Because juveniles have no prior experience of the environment along the migration route [42], these should better represent the endogenous migratory routes of the species, and prior to selection, represent a more unbiased subject for studies of the genetic basis of migration.

\section{Conclusion}

Our study on juvenile willow warblers supports the hypothesis that hybrids tend to follow an intermediate route during autumn migration compared to the parental populations. This finding also supports the hypothesis that the divergent blocks on chromosome 1 and 5 in willow warblers [28] may contain genes encoding migration direction. In species with known population genetic structure, such as the willow warbler, the here used qPCR-based SNP genotyping makes it possible to reveal details of the first-year migration that will be difficult to obtain with other methods. We showed that precise genotyping can be applied to DNA samples extracted from feather tips and specimen tissues, material that typically contain degraded DNA (around $100 \mathrm{bp}$ ), in agreement with previous studies on other species [43, 44], and therefore a convenient tool for studies combining DNA samples of different origins.

\section{Supplementary information}

Supplementary information accompanies this paper at https://doi.org/10. 1186/s40462-020-00209-7.

\footnotetext{
Additional file 1: Table S1. The DNA sample collection that have been used for SNP genotyping in this study, including the sample sizes, sample sources, sampling year and origin. Figure S1. $F_{\text {ST }}$ array results illustrating the genetic differentiation of $\sim 4000$ SNPS throughout the genome of willow warblers with the positions of the qPCR primers indicated. Table S2. The sequences of primers and probes for the four selected SNPS on chromosome 1 and 5. Figure S2. Examples of sample dual scatterplot of SNP genotyping results. Figure S3. Allele frequencies of the four selected SNPs on chromosome 1 and 5 in northern (upper pie charts)
} 
and southern populations (lower pie charts) in Scandinavia. Table S3. Comparison between SNP genotype results from this study and the whole-block genotype results from Lundberg et al. Table S4. SNP genotyping results from sites in Scandinavia. Sites with latitude $<60^{\circ}$ are regarded as southern population. Sites with latitude $>65^{\circ}$ are regarded as northern population. Table S5. SNP genotyping results from southern Europe in autumn (August-October). Table S6. SNP genotyping results from Africa in winter

\section{Acknowledgements}

We thank Magdalena Gajdošová and Pavel Munclinger from Charles University in Prague for providing the Cameron samples and Marjorie Sorenson from University of Cambridge, UK, for the samples from Zambia. Jane Jönsson supported with valuable guidance during the lab work. Dennis Hasselquist and Thomas Alerstam have joined the discussion of the project and provided valuable opinions. Violeta Caballero López, Alex Mackintosh and Mikkel Willemoes provided ideas about sample analyses and Hongkai Zhang commented on the manuscript

\section{Authors' contributions}

TZ did all the lab work, analyses and wrote the first draft of the manuscript. SB initiated and supervised the project. ML did the genomic analyses and located the highly fixed SNP markers for the study. SA, KL, MI and JMN contributed with the DNA samples from the non-breeding areas. All authors discussed the outcome of the results and provided comments on the draft. All authors read and approved the final manuscript.

\section{Funding}

The study was supported by grants from the Swedish Research Council (2017-03937) to SB and (621-2007-5930; 621-2010-5584, 621-2013-4361) to $S \AA$, and a Linnaeus grant from the Swedish Research Council (349-20078690) to the Centre for Animal Movement Research (CAnMove) and Lund University. The sample collection in Bulgaria was supported by grant from the Bulgarian Science Fund (DO02-277) to MI. Open access funding was provided by Lund University.

\section{Availability of data and materials}

The SNP genotyping data set are attached in the supplementary materials.

\section{Ethics approval}

The samples were collected according to legislation in the each of the different countries. An ethical permission from Lund-Malmö Djurförsöksetiska Nämnd (M45:14) was given to SB for collecting blood and feather samples in Sweden in association with mist-netting and ringing (SB Swedish ringing license $\mathrm{nr}$. 555). Feather samples from Portugal were collected under the licenses 86/2009, 122/2009/CAPT and 92/2010 issued by CEMPA/ICNF. Blood samples from Bulgaria were collected under permission 213/26.6.2009 issued by Ministry of Environment and Water of Bulgaria.

\section{Consent for publication}

Not applicable.

\section{Competing interests}

The authors declare that they have no competing interests.

\section{Author details}

'Department of Biology, Molecular Ecology and Evolution Laboratory, Lund University, Ecology Building, 22362 Lund, SE, Sweden. ${ }^{2}$ Institute of Biodiversity and Ecosystem Research, Bulgarian Academy of Sciences, 2 Gagarin str, 1113 Sofia, Bulgaria. ${ }^{3}$ Climate Impacts Research Centre, Department of Ecology and Environmental Sciences, Umeå University, 901 87 Umeå, SE, Sweden. ${ }^{4}$ Department of Biology, Evolutionary Ecology Unit, Lund University, Ecology Building, 22362 Lund, SE, Sweden.
Received: 3 January 2020 Accepted: 5 May 2020

Published online: 29 May 2020

\section{References}

1. Møller A, Garamszegi L, Peralta-Sánchez J, Soler J. Migratory divides and their consequences for dispersal, population size and parasite-host interactions. J Evol Biol. 2011;24(8):1744-55.

2. Irwin $\mathrm{DE}$, Irwin $\mathrm{JH}$. Siberian migratory divides: the role of seasonal migration in speciation. In: Birds of two worlds: the ecology and evolution of migration; 2005. p. 27-40.

3. Rohwer S, Irwin DE. Molt, orientation, and avian speciation. Auk. 2011;128(2): 419-25.

4. Irwin DE. Speciation: new migratory direction provides route toward divergence. Curr Biol. 2009;19(24):R1111-R3.

5. Veen T, Svedin N, Forsman JT, Hjernquist MB, Qvarnstrom A, Hjernquist KA, et al. Does migration of hybrids contribute to post-zygotic isolation in flycatchers? Proc Biol Sci. 2007;274(1610):707-12.

6. Rubolini D, Gardiazabal Pastor A, Pilastro A, Spina F. Ecological barriers shaping fuel stores in barn swallows Hirundo rustica following the central and western Mediterranean flyways. J Avian Biol. 2002;33(1):15-22.

7. Strandberg R, Klaassen RH, Hake M, Alerstam T. How hazardous is the Sahara Desert crossing for migratory birds? Indications from satellite tracking of raptors. Biol Lett. 2009;6(3):297-300.

8. Helbig AJ. Inheritance of migratory direction in a bird species: a crossbreeding experiment with SE-and SW-migrating blackcaps (Sy/via atricapilla). Behav Ecol Sociobiol. 1991;28(1):9-12.

9. Veen T, Hjernquist MB, Van Wilgenburg SL, Hobson KA, Folmer E, Font L, et al. Identifying the African wintering grounds of hybrid flycatchers using a multiisotope $(\delta 2 \mathrm{H}, 813 \mathrm{C}, 815 \mathrm{~N})$ assignment approach. PLoS One. 2014;9(5):e98075.

10. Yohannes $E$, Lee RW, Jochimsen MC, Hansson B. Stable isotope ratios in winter-grown feathers of great reed warblers Acrocephalus arundinaceus, clamorous reed Warblers $A$. stentoreus and their hybrids in a sympatric breeding population in Kazakhstan. Ibis. 2011;153(3):502-8.

11. Bensch S, Bengtsson G, Åkesson S. Patterns of stable isotope signatures in willow warbler Phylloscopus trochilus feathers collected in Africa. J Avian Biol. 2006;37(4):323-30.

12. Delmore KE, Fox JW, Irwin DE. Dramatic intraspecific differences in migratory routes, stopover sites and wintering areas, revealed using lightlevel geolocators. Proc R Soc B Biol Sci. 2012;279(1747):4582-9.

13. Delmore KE, Irwin DE. Hybrid songbirds employ intermediate routes in a migratory divide. Ecol Lett. 2014;17(10):1211-8.

14. Bowlin MS, Henningsson P, Muijres FT, Vleugels RH, Liechti F, Hedenström A. The effects of geolocator drag and weight on the flight ranges of small migrants. Methods Ecol Evol. 2010;1(4):398-402.

15. Taylor $\mathrm{P}$, Crewe T, Mackenzie S, Lepage D, Aubry $Y$, Crysler Z, et al. The motus wildlife tracking system: a collaborative research network to enhance the understanding of wildlife movement. Avian Conserv Ecol. 2017;12(1):8.

16. Ruegg K. Genetic, morphological, and ecological characterization of a hybrid zone that spans a migratory divide. Evolution. 2008;62(2):452-66.

17. Ruegg KC, Anderson E, Harrigan RJ, Paxton KL, Kelly J, Moore F, et al. Identifying migrant origins using genetics, isotopes, and habitat suitability. bioRxiv. 2016:085456.

18. Cramp S, Brooks DJ. Vol. Vl: Warblers. Oxford: Oxford University Press; 1992.

19. Hedenström A, Petterson J. Migration routes and wintering areas of willow warblers Phylloscopus trochilus (L.) ringed in Fennoscandia. Ornis Fenn. 1987; 64(4):137-43.

20. Lerche-Jørgensen M, Willemoes M, Tøttrup AP, Snell KR, Thorup K. No apparent gain from continuing migration for more than 3000 kilometres: willow warblers breeding in Denmark winter across the entire northern Savannah as revealed by geolocators. Mov Ecol. 2017;5(1):17.

21. Sokolovskis K, Bianco G, Willemoes M, Solovyeva D, Bensch S, Åkesson S. Ten grams and 13,000 km on the wing-route choice in willow warblers Phylloscopus trochilus yakutensis migrating from Far East Russia to East Africa. Mov Ecol. 2018;6(1):20.

22. Bensch S, Grahn M, Müller N, Gay L, Åkesson S. Genetic, morphological, and feather isotope variation of migratory willow warblers show gradual divergence in a ring. Mol Ecol. 2009;18(14):3087-96.

23. Chamberlain C, Bensch S, Feng X, Åkesson S, Andersson T. Stable isotopes examined across a migratory divide in Scandinavian willow warblers (Phylloscopus trochilus trochilus and Phylloscopus trochilus acredula) reflect their African winter quarters. Proc R Soc Lond Ser B Biol Sci. 2000;267(1438):43-8. 
24. Bensch S, Andersson T, Åkesson S. Morphological and molecular variation across a migratory divide in willow warblers, Phylloscopus trochilus. Evolution. 1999;53(6):1925-35.

25. Bensch S, Helbig AJ, Salomon M, Seibold I. Amplified fragment length polymorphism analysis identifies hybrids between two subspecies of warblers. Mol Ecol. 2002;11(3):473-81.

26. Larson KW, Liedvogel M, Addison B, Kleven O, Laskemoen T, Lifjeld JT, et al. Allelic variation in a willow warbler genomic region is associated with climate clines. PLoS One. 2014;9(5):e95252.

27. Liedvogel M, Larson KW, Lundberg M, Gursoy A, Wassenaar LI, Hobson KA, et al. No evidence for assortative mating within a willow warbler migratory divide. Front Zool. 2014;11(1):52.

28. Lundberg M, Liedvogel M, Larson K, Sigeman $H$, Grahn M, Wright A, et al. Genetic differences between willow warbler migratory phenotypes are few and cluster in large haplotype blocks. Evol Lett. 2017:1(3):155-68.

29. Richardson D, Jury F, Blaakmeer K, Komdeur J, Burke T. Parentage assignment and extra-group paternity in a cooperative breeder: the Seychelles warbler (Acrocephalus sechellensis). Mol Ecol. 2001;10(9):2263-73.

30. Helbig A. Genetic basis, mode of inheritance and evolutionary changes of migratory directions in palaearctic warblers (Aves: Sylviidae). J Exp Biol. 1996;199(1):49-55.

31. Tøttrup AP, Pedersen L, Thorup K. Autumn migration and wintering site of a wood warbler Phylloscopus sibilatrix breeding in Denmark identified using geolocation. Anim Biotelem. 2018;6(1):15.

32. Bibby C, Green R. Autumn migration strategies of reed and sedge warblers. Ornis Scand. 1981:12(1):1-12

33. Barton NH, Hewitt GM. Analysis of hybrid zones. Annu Rev Ecol Syst. 1985; 16(1):113-48.

34. Rabøl J. One-direction orientation versus goal area navigation in migratory birds. Oikos. 1978;30(2):216-23.

35. Åkesson S, Morin J, Muheim R, Ottosson U. Avian orientation at steep angles of inclination: experiments with migratory white-crowned sparrows at the magnetic north pole. Proc R Soc Lond Ser B Biol Sci. 2001;268(1479):1907-13.

36. Perdeck A. Two types of orientation in migrating starlings, Sturnus vulgaris $\mathrm{L}$. , and chaffinches, Fringilla coelebs L., as revealed by displacement experiments. Ardea. 1958;55(1-2):1-3.

37. Mouritsen $\mathrm{H}$. Spatiotemporal orientation strategies of long-distance migrants. Berlin: Avian migration: Springer; 2003. p. 493-513.

38. Strandberg R, Klaassen RH, Thorup K. Spatio-temporal distribution of migrating raptors: a comparison of ringing and satellite tracking. J Avian Biol. 2009;40(5):500-10.

39. Alerstam T, Hake M, Kjellén N. Temporal and spatial patterns of repeated migratory journeys by ospreys. Anim Behav. 2006;71(3):555-66.

40. Vega ML, Willemoes M, Thomson RL, Tolvanen J, Rutila J, Samaš P, et al. First-time migration in juvenile common cuckoos documented by satellite tracking. PLoS One. 2016;11(12):e0168940.

41. Milwright R. Post-breeding dispersal, breeding site fidelity and migration/ wintering areas of migratory populations of song thrush Turdus philomelos in the Western Palearctic. Ringing Migr. 2006;23(1):21-32.

42. Mouritsen $\mathrm{H}$. Long-distance navigation and magnetoreception in migratory animals. Nature. 2018:558(7708):50.

43. Campbell NR, Narum SR. Quantitative PCR assessment of microsatellite and SNP genotyping with variable quality DNA extracts. Consenv Genet. 2009;10(3):779-84.

44. Morin PA, McCarthy M. Highly accurate SNP genotyping from historical and low-quality samples. Mol Ecol Notes. 2007;7(6):937-46.

\section{Publisher's Note}

Springer Nature remains neutral with regard to jurisdictional claims in published maps and institutional affiliations.

Ready to submit your research? Choose BMC and benefit from:

- fast, convenient online submission

- thorough peer review by experienced researchers in your field

- rapid publication on acceptance

- support for research data, including large and complex data types

- gold Open Access which fosters wider collaboration and increased citations

- maximum visibility for your research: over $100 \mathrm{M}$ website views per year

At $\mathrm{BMC}$, research is always in progress.

Learn more biomedcentral.com/submissions 